\title{
Epidemiology of work-related injuries among insured construction workers in Iran
}

\author{
Seyed Esmaeil Hatami ${ }^{1}$, Mohammad Reza Ghotbi Ravandi ${ }^{2}$, Seyedeh Tayebeh Hatami ${ }^{3}$, Narges Khanjani ${ }^{4}$
}

${ }^{1}$ M.Sc. of Epidemiology, Addiction and Behavioral Sciences Research Center, North Khorasan University of Medical Sciences, Bojnurd, Iran

${ }^{2}$ Associate Professor, Department of Occupational Health, School of Public Health, Kerman University of Medical Sciences, Kerman, Iran

${ }^{3}$ M.Sc. Student, Department of Environmental Health Engineering, School of Public Health, Hamadan University of Medical Sciences, Hamadan, Iran

${ }^{4}$ Associate Professor, Environmental Health Engineering Research Center, Kerman University of Medical Sciences, Kerman, Iran

\section{Type of article: Original}

\begin{abstract}
Background and aim: Work-related injuries are among the most important health problems in developing countries, such as Iran. The purpose of this study was to determine the epidemiology of work-related injuries among construction workers who had been insured by the Iranian Social Security Organization (ISSO).

Methods: This is a cross-sectional study. The population included all construction workers who had a workrelated accident during 2012 in Iran, which were recorded in the ISSO database after inspection. The effects of independent variables on injuries were estimated by logistic regression. SPSS software version 18 was used for analyzing the data.

Results: Overall, 5352 work-related injuries were investigated. The incidence rate of fatal and nonfatal injuries was 0.07 in 1000 and 11.18 in 1000 workers, respectively. More than half of these accidents were due to careless activities. A younger age at the time of the accident $(\mathrm{OR}=0.98, \mathrm{CI}$ : $0.97-0.99, \mathrm{p}=0.001)$, being married $(\mathrm{OR}=1.37$, CI: $1.04-1.79, \mathrm{p}=0.02)$, place of accident ( $\mathrm{OR}=1.86$, CI: $1.18-2.92, \mathrm{p}=0.007)$, lack of information $(\mathrm{OR}=5.28, \mathrm{CI}$ : $1.57-17.75, \mathrm{p}=0.007)$, disrespect of safety regulations $(\mathrm{OR}=3.11, \mathrm{CI}: 1.87-5.17, \mathrm{p}=0.001)$, non-use of protective equipment $(\mathrm{OR}=2.98$, CI: 1.62-5.50, $\mathrm{p}=0.001)$, and defective equipment $(\mathrm{OR}=2.22$, CI: $1.18-4.20, \mathrm{p}=0.01)$ had a significant effect on the incidence of work-related injury.

Conclusions: The pattern of work-related injury in Iran was almost similar in regard to age, gender, cause and type of the accident, with other parts of the world.
\end{abstract}

Keywords: Epidemiology, Occupational accidents, Injuries, Iran

\section{Introduction}

Work-related injuries are among the most important consequences of industrialization in developing countries (1) and are now one of their most important health problems (1). Unintentional accidents are the second-leading cause of death in Iran (2). Although a lot of effort has gone into reducing work-related injuries, the incidence of these injuries remains high in Iran. The World Health Organization has regarded these events as an epidemic in public health and has considered them as extremely important health, economic, and social risk factors $(1,3)$. A recent study in the United States shows that the cost of fatal and nonfatal accidents in the construction industry was $\$ 11.5$ billion in 2002. The average cost of a single accident in construction was $\$ 27,000$, which is twice the cost of an accident in other industries (4). According to the statistics published in 2002 in Iran, the most common work accidents occur in the construction industry, and about $12 \%$ of workers are active in this sector $(5,6)$. This industry has employed the highest number of workers in Iran (5). Most work-related accidents are preventable, and

\section{Corresponding author:}

Associate Professor Narges Khanjani, Department of Epidemiology and Biostatistics, School of Public Health, Kerman University of Medical Sciences, Kerman, Iran. Tel/Fax: +983431325102, Email: n_khanjani@kmu.ac.ir Received: September 19, 2016, Accepted: July 28, 2017, Published: November 2017 iThenticate screening: June 08, 2017, English editing: October 08, 2017, Quality control: November 02, 2017 (C) 2017 The Authors. This is an open access article under the terms of the Creative Commons Attribution-NonCommercialNoDerivs License, which permits use and distribution in any medium, provided the original work is properly cited, the use is non-commercial and no modifications or adaptations are made. 
preventive policies have reduced the death rate of these accidents in many developed countries (7). The occurrence of work accidents is on the rise in the construction industry in Iran, and the severity of injuries caused by these accidents is increasing as well (8). Unfortunately, although the rate of work-related injuries is high in Iran, few studies have been published in regard to this issue from this country (9). Mehrdad et al.'s study over insured construction workers in Iran showed that fatal and nonfatal injury rates were 0.63 in 100,000 and 19.4 in 100,000 workers, respectively (10). Occupational accident statistics are published annually in many countries, but they are not thoroughly reliable because of under-reporting (11). Fear of deportation, losing wages and benefits, agreements between the employer and workers about repayment, unawareness of the compensation system, and the probability of rejecting the workers claims are typical reasons for not reporting minor injuries (12). In addition, lack of a comprehensive and standard registration systems has caused difficulty in comparing the statistics (11). Data collection and reporting are the first steps for designing and performing prevention programs (12). This study aimed to determine the epidemiology of work-related injuries and the individual's characteristics associated with workrelated injuries, among Iranian insured construction workers in 2012.

\section{Material and Methods}

This was a cross-sectional study. The population included all insured construction workers in Iran in 2012. Individual-level data for 5352 hospitalized workers in Iran were collected from a population of 475,830 insured construction workers. Recorded information of each individual was available in the ISSO electronic database which is based on inspection reports. In this study, required data were collected from the statistics and socioeconomic calculations office of the Social Security Organization Headquarters in Tehran. According to Article 60 of Iran's social security law, work-related injuries are defined as unpredictable accidents that happen under the influence of external factors while the insured workers are at duty. This definition also includes events that occur while commuting to work or saving other workers $(13,14)$. In this study, the annual incidence rate of injury (per 1000 workers) was calculated by dividing all insured construction workers who were injured in 2012 (nominator) by all construction workers who were insured by the Iranian Social Security Organization (ISSO) in the same year (denominator). In order to determine the effect of independent variables on the incidence of injuries, logistic regression analysis was conducted. In this analysis, the event (injury) was considered as the dependent or response variable; younger age, being married, place of accident and causes of accident were considered as independent variables (risk factors). Variables were adjusted for age and gender. The odds ratios and their $95 \%$ confidence intervals were calculated. SPSS (SPSS Inc., Chicago, Illinois, USA) version 18 was used for all statistical analysis. P-values equal or less than 0.05 were considered significant. Permanent total disability was defined as any kind of injury other than death which permanently or extensively makes the worker incapable of doing proper job tasks or leads to loss of function in a body part or complete loss of a limb. Workers with $66 \%$ or more disability are called totally disabled (15). Partial disability is any kind of injury other than death; total disability leads to loss of functional abilities or complete/partial limb amputation. Workers with between $33 \%$ and $66 \%$ disability due to work-related accidents are called partially disabled (15). Fixed compensation or wage compensation during illness refers to the funds that are paid during illness, pregnancy, or temporary unemployment according to the Social Security Act to people for any kind of injury other than death or disabilities (total and partial) that cause loss of function for a few days. Workers with between $33 \%$ and $10 \%$ disability are included in this category (15). Injuries caused by carelessness are injuries related to factors such as not paying attention to the task, working in a hurry, underestimating the risk, being adventurous or overconfident, working alone (especially during night hours), or imbalanced speed during work. Injuries were also caused by rage, joking, and arguing; some causes were unrecorded or unclassified.

\section{Results}

In 2012, 5352 insured workers, including 5326 men (99.5\%) and 26 women (0.5), were injured in Iran. Among them, $75.2 \%$ were married and the mean $\pm \mathrm{SD}$ of the injured workers age was $34.05 \pm 1.07$ years. Mean age was higher in women compared with men. Most work-related injuries occurred among workers between the age of 20 and 29 years and between 7 and 10 a.m. (Table 1). The incidence rates of injuries among male and female workers were 11.2 and 125.6 in 1000 workers, respectively. Further, the fatal and nonfatal injury rates were 0.07 in 1000 and 11.18 in 1000 workers, respectively (Table 2). In total, 33 cases were fatal, which all had occurred among male workers. The fatal and nonfatal accidents ratios were 6.9 in 100,000 and 1117.8 in 100,000 workers, respectively. Over two-thirds $(62 \%)$ of all injuries occurred in workers under 35 years, while the highest percentage of fatal injuries was in the workers over 35 years. Without considering the number of insured workers in each province, Bushehr (6.97\%) and Azerbaijan (6.80\%) had the most and North Khorasan (0.65\%) and South Khorasan (0.54\%) had the least accidents. The majority of injured workers (92.3\%) recovered completely. 
Table 1. Demographic information of injured workers in Iran, 2012.

\begin{tabular}{|c|c|c|c|}
\hline \multicolumn{2}{|l|}{ Variables } & $\mathrm{n} /$ Mean $\pm \mathrm{SD}$ & $\%$ \\
\hline \multirow{3}{*}{ Age (years) } & Men & $34.04 \pm 10.68^{*}$ & - \\
\hline & Women & $35.96 \pm 8.22^{*}$ & - \\
\hline & Total & $34.05 \pm 1.07^{*}$ & - \\
\hline \multirow[t]{2}{*}{ Gender } & Male & 5326 & 99.5 \\
\hline & Female & 26 & 0.5 \\
\hline \multirow[t]{2}{*}{ Marital status } & Single & 1326 & 24.8 \\
\hline & Married & 4026 & 75.2 \\
\hline \multirow[t]{7}{*}{ Age group (year) } & $10-19$ & 168 & 3.1 \\
\hline & $20-29$ & 1977 & 37 \\
\hline & $30-39$ & 1718 & 32.1 \\
\hline & $40-49$ & 909 & 17 \\
\hline & $50-59$ & 477 & 8.9 \\
\hline & $60-69$ & 85 & 1.6 \\
\hline & $70+$ & 18 & 0.3 \\
\hline \multirow[t]{2}{*}{ Place of accident } & Inside & 5178 & 96.7 \\
\hline & Outside & 174 & 3.3 \\
\hline \multirow[t]{8}{*}{ Time of accident } & $1.1-4$ & 67 & 1.25 \\
\hline & $4.1-7$ & 86 & 1.61 \\
\hline & $7.1-10$ & 1526 & 28.51 \\
\hline & $10.1-13$ & 1492 & 27.88 \\
\hline & $13.1-16$ & 1385 & 25.88 \\
\hline & 16.1-19 & 664 & 12.40 \\
\hline & $19.1-22$ & 77 & 1.44 \\
\hline & $22.1-1$ & 55 & 1.03 \\
\hline
\end{tabular}

Table 2. The incidence rate of work-related injuries among Iranian insured construction workers (per 1000 worker) in 2012.

\begin{tabular}{|l|l|l|l|}
\hline Variable & Gender & $\mathrm{n}$ & $\%$ \\
\hline Insured workers & Men & 475623 & 99.96 \\
\cline { 2 - 4 } & Women & 207 & 0.04 \\
\cline { 2 - 4 } & Total & 475830 & 100 \\
\hline \multirow{3}{*}{ Injured workers } & Men & 5326 & 99.5 \\
\cline { 2 - 4 } & Women & 26 & 0.5 \\
\cline { 2 - 4 } & Total & 5352 & 100 \\
\hline Incidence rate, number of events in 1000 workers & Men & 11.2 & - \\
\cline { 2 - 4 } & Women & 125.6 & - \\
\cline { 2 - 4 } & Total & 11.3 & - \\
\hline
\end{tabular}

Between 7 to $8 \%$ of occupational accidents lead to disability (either partial or total) and death. Almost, $12.57 \%$ of injured workers were hospitalized; the mean $\pm \mathrm{SD}$ of the days that the workers spent in the hospital were $1.6 \pm 11.6$ days and $87.8 \%$ of the injured were cured by outpatient treatment. The mean $\pm \mathrm{SD}$ for the days of outpatient treatment was $55.3 \pm 53.4$ days (Table 3 ). More than half of the accidents were due to carelessness (55\%). Table 4 shows the accident types in injured individuals. Slipping and falling from a height (32.4\%) was the most common. The most frequent injured body parts in accidents were the hands $(26.46 \%)$ and legs $(26.16 \%)$, respectively (Table 4). Results showed age has a significant effect on the occurrence of injuries $(\mathrm{OR}=0.98, \mathrm{CI}$ : $0.97-0.99, \mathrm{p}=0.001)$ and for each one-year increase in age, the risk of accidents decreased by about $0.2 \%$. Also, being married $(\mathrm{OR}=1.37, \mathrm{CI}$ : $1.04-1.79, \mathrm{p}=0.02$ ) was a risk factor, in which the class of single was considered as the reference, the amount of chance was equal to 1.37 , means that the chances of married workers exposure to injury in different classes is 1.37 times higher comparing to single workers. Also, place of accident ( $\mathrm{OR}=1.86$, CI: 1.18-2.92, $\mathrm{p}=0.007$ ) significantly increased the risk $(86 \%)$, and accidents occurred more in the outdoors. Also, lack of information $(\mathrm{OR}=5.28, \mathrm{CI}$ : $1.57-17.75, \mathrm{p}=0.007)$, disrespect of safety regulations $(\mathrm{OR}=3.11$, CI: $1.87-5.17, \mathrm{p}=0.001)$, non-use of protective equipment $(\mathrm{OR}=2.98, \mathrm{CI}: 1.62-5.50, \mathrm{p}=0.001)$, as well as defective equipment $(\mathrm{OR}=2.22, \mathrm{CI}: 1.18-4.20, \mathrm{p}=0.01)$ were the most prevalent risk factors for injuries among Iranian workers (Table 5). 
http://www.ephysician.ir

Table 3. Prevalence of type of injury and treatment among the Iranian insured construction workers in 2012.

\begin{tabular}{|c|c|c|c|}
\hline \multicolumn{2}{|l|}{ Variable } & $\mathrm{n}$ & $\%$ \\
\hline \multirow[t]{5}{*}{ Accident results } & Death & 33 & 0.6 \\
\hline & Total disability & 46 & 0.9 \\
\hline & Partial disability & 77 & 1.4 \\
\hline & Fixed compensation & 255 & 4.8 \\
\hline & Complete recovery & 4941 & 92.3 \\
\hline \multirow[t]{6}{*}{ Inpatient treatment (day) } & 1 & 156 & 23.14 \\
\hline & $2-3$ & 220 & 32.64 \\
\hline & $4-7$ & 122 & 18.10 \\
\hline & $8-14$ & 63 & 9.35 \\
\hline & $>14$ & 113 & 16.77 \\
\hline & Total & 674 & 100 \\
\hline \multirow[t]{6}{*}{ Outpatient treatment (day) } & 1 & 221 & 4.74 \\
\hline & $2-3$ & 23 & 0.50 \\
\hline & $4-7$ & 180 & 3.86 \\
\hline & $8-14$ & 406 & 8.71 \\
\hline & $>14$ & 3831 & 82.19 \\
\hline & Total & 4661 & 100 \\
\hline
\end{tabular}

Table 4. Prevalence of accident based on type, causes, and injured body part.

\begin{tabular}{|c|c|c|c|}
\hline \multicolumn{2}{|l|}{ Variable } & $\mathrm{n}$ & $\%$ \\
\hline \multirow[t]{15}{*}{ Accident type } & Slipping and falling from height & 1832 & 34.2 \\
\hline & Object collision & 97 & 1.8 \\
\hline & Caught in or compressed by equipment or objects & 278 & 5.2 \\
\hline & Laceration or Amputation & 364 & 6.8 \\
\hline & Broken limbs & 694 & 13 \\
\hline & Falling objects & 532 & 9.9 \\
\hline & Electricity shock & 46 & 0.8 \\
\hline & Building collapse (buried under debris) & 57 & 1.1 \\
\hline & Burns & 113 & 2.1 \\
\hline & Accidents due to using hand tools & 117 & 2.2 \\
\hline & Accidents due to using machine tools & 186 & 3.5 \\
\hline & Accident due to moving objects & 292 & 5.5 \\
\hline & Vehicle collision & 81 & 1.5 \\
\hline & Physical strikes or sprains & 515 & 9.6 \\
\hline & Others & 148 & 2.8 \\
\hline \multirow[t]{8}{*}{ Cause of accident } & Defective equipment & 145 & 2.7 \\
\hline & Unguarded equipment & 242 & 4.5 \\
\hline & Carelessness & 2945 & 55 \\
\hline & Improper physical environment & 31 & 0.3 \\
\hline & Lack of information & 66 & 0.9 \\
\hline & Non-use of protective equipment & 201 & 3.7 \\
\hline & Disrespect of safety regulations & 362 & 6.8 \\
\hline & Other causes & 1360 & 25.4 \\
\hline \multirow[t]{10}{*}{ Injured body part } & Head and neck & 502 & 9.37 \\
\hline & Upper limbs (except fingers and hands) & 468 & 8.75 \\
\hline & Hands & 1416 & 26.46 \\
\hline & Fingers & 857 & 16.01 \\
\hline & Trunk & 109 & 2.04 \\
\hline & Lower limbs (except toes and legs) & 157 & 3.21 \\
\hline & Legs & 1400 & 26.16 \\
\hline & Toes & 126 & 2.35 \\
\hline & Total body & 83 & 1.55 \\
\hline & Others & 234 & 4.37 \\
\hline
\end{tabular}


Table 5. Factors related to injuries in insured construction workers in Iran, 2012.

\begin{tabular}{|l|l|l|l|l|}
\hline Variable & Levels & OR & $95 \%$, CI & p-value \\
\hline Younger age & Years & 0.98 & $0.97-0.99$ & 0.001 \\
\hline Gender & Female & Reference & & \\
& Male & 1.48 & $0.43-5.12$ & 0.52 \\
\hline Being married & Single & Reference & & \\
& Married & 1.37 & $1.04-1.79$ & 0.02 \\
\hline Place of accident & Outdoors & Reference & & \\
& Indoors & 1.86 & $1.18-2.92$ & 0.007 \\
\hline Cause of accident & Unguarded equipment & Reference & & \\
& Lack of information & 5.28 & $1.57-17.75$ & 0.007 \\
& Other causes & 2.82 & $1.94-4.09$ & 0.001 \\
& Disrespect of safety regulations & 3.11 & $1.87-5.17$ & 0.001 \\
& Non-use of protective equipment & 2.98 & $1.62-5.50$ & 0.001 \\
& Carelessness & 3.48 & $2.45-4.93$ & 2.32 \\
& Defective equipment & 2.22 & $1.18-4.20$ & 0.01 \\
& Improper physical environment & 2.08 & $0.62-6.95$ & 0.23 \\
\hline
\end{tabular}

OR: Odds Ratio; CI: Confidence Interval

\section{Discussion}

In this study, the incidence rate of work-related accidents among insured construction workers in Iran was 11.3 per thousand workers. This number is greater than the results presented in Moradinazar's study in Ilam, Iran, in 20062009 (8.2 per thousand) and Halvani's study in Yazd, Iran, in 2006-2011 (4.1 per thousand workers) (16-19). However, this difference could be due to using different methods and reference populations or under-reporting injuries to the responsible organization, in other studies. Furthermore, small and less significant injuries might not get reported, as they might seem nonsignificant in comparison with the high number of other major injuries happening in this industry. However, the Iranian Social Security Organization has insured the highest number of construction workers in Iran. The present study shows that most accidents have occurred between 7 to 10 a.m. These results are similar to those in Vatani-Shoaa et al.'s study in Kerman, Iran; Halvani et al.'s study in Yazd, Iran; and Liao et al.'s study in Taiwan $(8,19,20)$. The reason might be the higher work load or dangerous activities that are predominant during these hours. The ratio of fatal and nonfatal accidents in this study was 6.94 and 1117.84 in 100,000 . It seems that the low rate of fatal accidents is because of improvements in medical facilities, the possibility of immediate clinical treatment in workplaces, and the establishment of worker health care units and centers inside the workshops and workplaces. The results of our study show that $12.57 \%$ of the workers were hospitalized; and the direct costs of medical care and indirect cost of lost time and human resources along with the future costs of disability would have been considerable. Our results are similar to Halvani et al.'s, and Moradinazar et al.'s studies from Iran, Colak et al.'s study from Turkey, Jeong et al.'s study in South Korea, and Huk's study in the United States, which all showed that one of the most important risk factors in work-related accidents is slipping and falling from a height $(16,19,21-23)$. Using safety equipment such as safety belts, helmets, appropriate shoes, work clothes, gloves, hooks, scaffolds, and danger tapes is essential for preventing falls and reducing dangerous consequences. According to Article 85 of the Islamic Republic of Iran's Work Act, in order to protect workers' health, it is necessary for all workplaces, employers, workers, and apprentices to respect all safety regulations. In this study, married workers were more vulnerable to work-related accidents, which led to partial or total disability. The calculations showed that the probability of facing an injury was more in married workers than single ones.

A study conducted in Turkey also showed that married workers were more involved in work-related accidents (22). These results are inconsistent with Vatani-Shoaa et al.'s study in Kerman and Bahrampour et al.'s study in Yazd (5, 8 ), which showed single workers were more likely to get injured. The reason for this finding in our study might be that married workers experience more stress from family issues, have more financial problems, and may have multiple jobs. In this study, most events occurred in workers between 20 to 29 years of age; and about $62 \%$ of them occurred in workers less than 35. Halvani et al.'s study in Yazd, Iran and Jeong et al.'s in South Korea showed that the number of injured workers in the 20- to 29-year-old age group is remarkable compared with that of the other groups, whereas Liao et al.'s study in Taiwan showed that the number of injured workers in the 35- to 44-year-old age group was much more compared with that of other age groups $(19,20,23)$. These results show that young, inexperienced workers are at a higher risk due to less stress management, lack of experience, not taking safety 
regulations seriously, lack of employer supervision, and lack of appropriate education for using safety equipment. Determining the cause of work accidents is an important topic in occupational epidemiology. Unfortunately, the causes of accidents had not been accurately addressed in the records, and $25 \%$ of the causes were classified under the unknown category. Improper classification in the forms has led to loss of necessary information. In spite of all these problems, it was still the main source of our available information. Although in many developing countries, i.e., Iran, high-quality information is limited, analyzing the available data can still be useful (24) and provide an outline of the real situation. Furthermore, many researchers claim that, in spite of the limitations in high-quality information, current data are still worth attention because they can help in setting priorities and suggesting preventive strategies (25). In this study, the most important causes of work-related injuries were lack of information, defective equipment, disrespect for safety regulations and non-use of protective equipment. These findings match Moradinazar et al.'s study in Iran, Clock et al.'s study in Turkey, and Larsson et al,'s study in Australia, which reported that the most important factors in work-related injuries are lack of employers' supervision and lack of using safety equipment $(16,22,26)$. Lack of experience and information was mentioned as the two important factors for occupational accidents in Halvani et al.'s study in Iran (19) as well. Urbanization and governmental support for retrofitting old buildings in the recent years, in Iran has led unemployed youth to migrate from villages to cities and has increased the number of unprofessional and unskilled workers. Therefore, to reduce the number of work-related accidents in the construction section, cooperation and coordination between the supervising institutions, i.e., the Civil Engineering Authority, Ministry of Labor and Social Welfare, Vocational Education Institutions, Housing and Urban Development organizations, Ministry of Health, and Medical Education, Safety and Technical Committees, the Media and Labor Organizations is required. The strengths of this study are the fact that we included all data from one complete year and that the physical examination of the injured workers was done by reliable doctors working with the Social Security Organization. Also, the medical forms and details of the accidents were completed by physicians and company inspectors, which were trained and reliable information sources. The limitations in this study include possible under-reporting of occupational injuries and not recording the details of the accident and the victims.

\section{Conclusions}

The pattern of work-related injuries in Iran was almost similar to that of many other developing countries, and the risk factors were place of accident, followed by being male, married, younger age, lack of information, disrespect of safety regulation, non-use of protective equipment, and using defective equipment. Cooperation with international organizations, i.e., the World Health Organization (WHO) and the International Labor Organization (ILO), in regional and trans-regional levels is necessary to use their experience and conduct successful programs for promoting workers' health.

\section{Acknowledgments:}

We acknowledge the Iranian Social Security Organization, which provided the data for this study. This article was part of a master thesis in epidemiology.

\section{Conflict of Interest:}

There is no conflict of interest to be declared.

\section{Authors' contributions:}

All authors contributed to this project and article equally. All authors read and approved the final manuscript.

\section{References:}

1) Hämäläinen P. The effect of globalization on occupational accidents. Safety Science. 2009;47(6):733-42. DOI: $10.1016 /$ j.ssci.2008.01.011

2) Naghavi M, Abolhassani F, Pourmalek F, Lakeh MM, Jafari N, Vaseghi S, et al. The burden of disease and injury in Iran 2003. Population health metrics. 2009;7(1):9. DOI: 10.1186/1478-7954-7-9, PMID: 19527516, PMCID: PMC2711041

3) Karvonen M. Epidemiology in the context of occupational health. Epidemiology of Occupational Health WHO M Karvonen \& MI Mikheev WHO. 1986:1-15.

4) Waehrer GM, Dong XS, Miller T, Haile E, Men Y. Costs of occupational injuries in construction in the United States. Accident Analysis \& Prevention. 2007;39(6):1258-66. DOI: 10.1016/j.aap.2007.03.012, PMCID: PMC2491397 
5) Bahrampour A, Nodoushan RJ, Shoaa JV. Five-year epidemiological study and estimation of accidents distribution in construction industry workers in yazd city by the year 2011 by applying time series model. Journal of Kerman University of Medical Sciences. 2009;16(2):156-64.

6) Hatami SE, Khanjani N, Alavinia SM, Ravandi MRG. Injuries and their burden in insured construction workers in Iran, 2012. International journal of injury control and safety promotion. 2016:1-8. DOI: 10.1080/17457300.2015.1132734, PMID: 26787067

7) Kletz TA. Learning from accidents: Gulf Professional Oxford, UK; 2001.

8) Vatani-Shoaa J, Salasi M, Bahrampour A, Raei M, Asadi M, Jafari-Nodoushan R, et al. An epidemiological study of accidents among construction workers in Kerman. Knowledge \& Health Journal. 2011;5(4):32-6.

9) Hämäläinen P, Takala J, Saarela KL. Global estimates of occupational accidents. Safety Science. 2006;44(2):137-56. DOI: 10.1016/j.ssci.2005.08.017

10) Mehrdad R, Seifmanesh S, Chavoshi F, Aminian O, Izadi N. Epidemiology of occupational accidents in iran based on social security organization database. Iran Red Crescent Med J. 2014;16(1):e10359. DOI: 10.5812/ircmj.10359, PMCID: PMC3964417

11) Takala J. Global estimates of fatal occupational accidents. Epidemiology-Baltimore. 1999;10(5):640-6. doi: 10.1097/00001648-199909000-00034

12) Shannon HS, Lowe GS. How many injured workers do not file claims for workers' compensation benefits? American journal of industrial medicine. 2002;42(6):467-73. DOI: 10.1002/ajim.10142

13) Williams CA. An international comparison of workers' compensation: Springer Science \& Business Media; 1991. doi: 10.1007/978-94-011-3872-7

14) Baker S, O'Neill B, Ginsburg M, Li G. The Injury Fact Book 1992. Oxford University Press, New York. 1992.

15) ISS Orginaization. Book of Legislations, Wage Compensation during Disease, In: ISS Orginaization (Ed.). Arithmetic\& Recalculation Unit Publication, Tehran, Iran. 2000.

16) Moradinazar M, Kurd N, Farhadi R, Amee V, Najafi F. Epidemiology of work-related injuries among construction workers of Ilam (Western Iran) during 2006-2009. Iranian Red Crescent Medical Journal. 2013;15(10). DOI: 10.5812/ircmj.8011, PMCID: PMC3950784

17) Bakhtiyari M, Delpisheh A, Riahi SM, Latifi A, Zayeri F, Salehi M, et al. Epidemiology of occupational accidents among Iranian insured workers. Safety Science. 2012;50(7):1480-4. DOI: 10.1016/j.ssci.2012.01.015

18) Dong X, Platner JW. Occupational fatalities of Hispanic construction workers from 1992 to 2000. American Journal of Industrial Medicine. 2004;45(1):45-54. DOI: 10.1002/ajim.10322

19) Halvani G, Jafarinodoushan R, Mirmohammadi S, Mehrparvar A. A survey on occupational accidents among construction industry workers in Yazd city: Applying Time Series 2006-2011. J Occup Health Epidemiol. 2012;1(1):1-8. doi: 10.18869/acadpub.johe.1.1.1

20) Liao C-W, Perng Y-H. Data mining for occupational injuries in the Taiwan construction industry. Safety science. 2008; 46(7):1091-102. DOI: 10.1016/j.ssci.2007.04.007

21) $\mathrm{Hu} \mathrm{K}$, Rahmandad H, Smith - Jackson T, Winchester W. Factors influencing the risk of falls in the construction industry: a review of the evidence. Construction Management and Economics. 2011;29(4):397-416. doi: 10.1080/01446193.2011.558104

22) Colak B, Etiler N, Bicer U. Fatal occupational injuries in the construction sector in Kocaeli, Turkey, 19902001. Industrial Health. 2004;42(4):424-30. doi: 10.2486/indhealth.42.424

23) Jeong BY. Occupational deaths and injuries in the construction industry. Applied Ergonomics. 1998;29(5):355-60. doi: 10.1016/S0003-6870(97)00077-X

24) Smith GS. Public health approaches to occupational injury prevention: do they work? Injury Prevention. 2001;7(suppl 1):i3-i10. doi: 10.1136/ip.7.suppl_1.i3, PMID: 11565968, PMCID: PMC1765411

25) Lortie M, Rizzo P. The classification of accident data. Safety Science. 1998;31(1):31-57. doi: 10.1016/S0925-7535(98)00053-8

26) Larsson TJ, Field B. The distribution of occupational injury risks in the Victorian construction industry. Safety Science. 2002;40(5):439-56. DOI: 10.1016/S0925-7535 (01) 00015-7 